\title{
A Comparative Study between Santulli Ileostomy and Loop Ileostomy
}

\author{
Dr. V.Leela Kumar, M.S, M.Ch ${ }^{1}$, Dr. K.V.Sathyanarayana, M.S, M.Ch ${ }^{2}$ \\ ${ }^{1}$ Assistant Professor: Department Of Paediatric Surgery, Niloufer Hospital, Osmania Medical College, \\ Hyderabad \\ ${ }^{2}$ Assistant Professor: Department Of Paediatric Surgery, Niloufer Hospital, Osmania Medical College, \\ Hyderabad
}

\begin{abstract}
:
Aim: Loop ileostomy has high complication rates and causes much patient inconvenience. This study was performed to compare the outcome of Santulli ileostomy versus loop ileostomy in newborns requiring enterostomy as diversion.

Patients and Methods: From July 2010 to July 2015, all patients requiring laparotomy and a de-functioning proximal protective loop ileostomy considered advisable were chosen for this study. Patients were randomly assigned to undergo either Santulli ileostomy or classical loop ileostomy as the diversion procedure.

Results: A total of 28 diversion procedures were performed over the period. In 10 cases Santulli ileostomy and 18 loop ileostomy was done. NEC Stage 3, complicated Meconium Ileus, Total Colonic Aganglionosis and perforation of ileum were the common conditions requiring laparotomy in neonates. In patients with loop ileostomy, overall complications in majority were peri-stomal skin excoriations, prolapsed of the proximal and distal bowel loops, electrolyte and fluid losses, and failure to gain weight. It was observed that the complication rate is high compared to Santulli ileostomy. Two patients developed obstruction following ileostomy closure which needed reoperation.

Conclusion: Santulli ileostomy is effective and feasible as a diversion procedure and has reduced morbidity and complication rates. It can be used as an alternative to loop ileostomy.

Key words: Neonates, Santulli Ileostomy, Loop Ileostomy, NEC, TCA, Meconium Ileus.
\end{abstract}

\section{Introduction}

In case of emergency laparotomy for intestinal perforation and obstruction for neonates, surgeons are faced with difficult decision to perform stoma for fecal diversion, and an even more difficult task is explaining the need for stoma to parents. Creation of a diverting stoma has its own set of complications including stomal retraction, prolapse, or necrosis, Para-ileostomy infection/abscess and fistula, intestinal obstruction, skin irritation/excoriation, mucosal ulceration, offensive odors, diarrhea, and hemorrhage [1]. The need for frequent change of the costly ileostomy appliances because of the leakage of liquid stools, following loss of seal imposes great financial burden, especially in developing countries. A need for second surgery for closure of stoma adds on to financial burden and unnecessary delays due to non prioritization of stoma closure due to high case volume. The closure of the intestinal stoma is also frequently followed by complications in $17 \%-27 \%$ of patients $[2,3]$.

These complications include fever, wound infection, abdominal septic complications, leak from ileostomy closure, intestinal obstruction, incisional hernia, and death.We designed this prospective study to assess the feasibility and outcome of proximal Santulli ileostomy in place of a de-functioning proximal loop ileostomy in patients treated by proximal diversion of small bowel. The construction of Santulli ileostomy was based on the concept of the currently well-accepted need to utilize the normal colonic reabsorption of fluid and electrolytes that helps in better weight gain and reduced complication rate. A comparison was made between Santulli ileostomy and loop ileostomy in terms of complications and outcome.

\section{Material And Methods}

The present study was conducted at Niloufer Hospital, Osmania Medical College India, from July 2010 to July 2015. Patients of neonatal age group who underwent explorative laparotomy for small bowel perforation or obstruction and in whom a decision to perform a proximal diversion stoma on the basis of the following intraoperative findings: multiple perforations, edematous and inflamed bowel, adherent loops of bowel, and insecure anastomosis, were chosen for the study. Patients were randomly assigned to undergo either a Santulli ileostomy or classical loop ileostomy as a diversion procedure. 
There are about 18 loop ileostomies done for NEC perforations $(n=4)$, Neonatal intestinal obstructions $(n=8)$, Total Colonic Aganglionosis (6). Ten are Santulli ileostomies, done for NEC perforations $(n=2)$, Neonatal obstructions $(n=6)$, TCA $(\mathrm{N}=2)$. There are 17 male babies and 11 female babies.

Patients who died within 5 days of surgery unrelated to the surgical complication and patients who were lost to follow up were excluded from the study.

Table 1: Characteristics of cases

\begin{tabular}{|l|l|l|l|l|l|}
\hline S. No & Clinical Condition & No. Of Cases & M/F & Loop Ileostomy & Santulli Ileostomy \\
\hline 1. & Nec Perforation Intestinal & 6 & $4 / 2$ & 4 & 2 \\
\hline 2. & $\begin{array}{l}\text { Neonatal } \\
\text { Obstruction }\end{array}$ & $9 / 5$ & 8 & 6 \\
\hline 3. & Total Colonic Aganglionosis & 8 & $4 / 4$ & 6 & 2 \\
\hline 4. & Total & 28 & $17 / 11$ & 18 & 10 \\
\hline
\end{tabular}

Technique of Santuille Ileostomy Construction

At laparotomy after dealing with primary pathology and performing necessary procedure, patients underwent either Santulli ileostomy or loop ileostomy. Santulli ileostomy is performed by bringing out the proximal loop of divided bowel out as ostomy and the distal end is re anastomosed to proximal bowel about 5 $\mathrm{cm}$ proximal to the ostomy site in end to side manner. In loop ileostomy both the loops of bowel are exteriorized as ostomy. A detailed record of the day on which Santulli ileostomy started functioning, drainage, weight loss, dehydration, fluid requirements sepsis, excoriation any feature suggestive of anastomotic leak, or any other complication was maintained.. All the patients were regularly followed up in the outpatient department for complications.
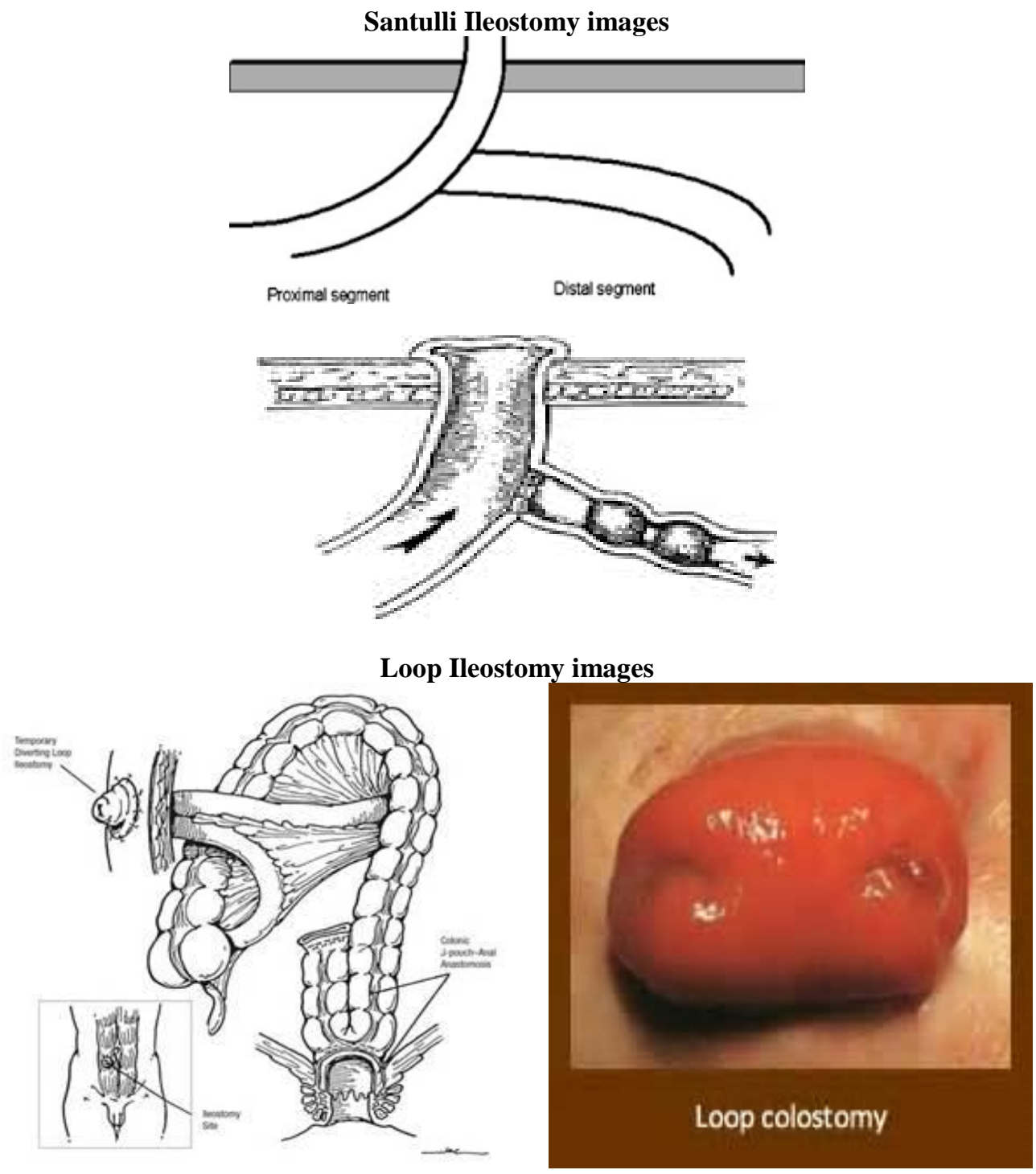


\section{Results}

Over a period of 5years from July 2010 to July 2015 a total of 28 diversion procedures were performed. Out of the 28 diversion procedures, 18 were conventional loop ileostomy and 10 were Santulli ileostomy as described above. Patients ranged from 1day to 45 days with mean age of 18 days. Majority of patients were male $(>60 \%)$.

Preoperative diagnosis was NEC perforation in 6 cases, Neonatal intestinal obstruction 14 cases, and total colonic Aganglionosis 8 cases. Duration of symptoms ranged from 1 to 5 days. The most common symptoms were abdominal distension, bilious vomiting, not passed meconium. Among presenting signs all the patients had tachycardia. Signs of peritonitis were present in 8 patients with masked liver dullness, free fluid in abdomen (4), and seven patients presented with severe dehydration and shock.

Erect X-ray showed air under diaphragm in 10 cases, dilated bowel loop in 24 cases, and ground glass appearance in 7 cases. Abdominal ultrasound showed moderate free fluid in 10 of the cases and dilated loops in 28 cases.

During the period of study 4 patients died in immediate postoperative period, due to unrelated procedure, and related complications were due to septicemia and multi-organ failure and these cases were excluded from the study.

In majority of patients (64\%) Santulli ileostomy started functioning on fifth postoperative day while in rest from second day. Ileostomy output ranged from $50-100 \mathrm{~mL} /$ day with mean of $50 \mathrm{~mL}$. One patient who had developed signs of peritonitis was re-operated and at anastomosis site leak was found.

In loop ileostomy group the main complication was peri-stomal skin excoriation which required prolonged regular dressing in all 18 cases. The ostomy output was between 100-200 ml/day. Two patients developed severe dehydration following high output from stoma and required hospitalization for electrolyte abnormalities and were managed with intravenous fluid. There was one case of early necrosis of stoma and retraction which required operation and stoma revision. The patients underwent ileostomy closure between 2 to 4 months with Santulli ileostomy as they gained weight early (mean 10 weeks) as compared to patients with loop ileostomy. The main complication following ileostomy closure was wound infection (8), which resolved with regular dressing and antibiotics. Two patients developed obstruction following closure, one of them required reoperation. Patients were followed up for a period of 6 months with one patient presenting with obstruction which required reoperation and adhesion release (Tables. 2).

Table 2: Complications and morbidity following Santullie ileostomy and loop ileostomy

\begin{tabular}{|l|l|l|l|}
\hline S. No. & Type Of Complication & Loop Ileostomy & Santulli Ileostomy \\
\hline 1. & Skin excoriation & 18 & 3 \\
\hline 2. & Ostomy prolapsed & 3 & 0 \\
\hline 3. & Anastomotic leak & 0 & 1 \\
\hline 4. & Severe dehydration & 2 & 0 \\
\hline 5. & Stoma retraction, necrosis & 2 & 0 \\
\hline 6. & Failure to thrive & 12 & 0 \\
\hline 7. & Adhesive intestinal obstruction & 0 & 1 \\
\hline 8. & Total no. of complications & 18 & 5 \\
\hline
\end{tabular}

\section{Discussion}

In the first report of loop ileostomy by Turnbull and Weakley [4] in 1966 it has gained popularity as a method of fecal diversion to protect distal anastomosis. The routine use of loop ileostomy to protect the distal anastomosis is much debated, and the literature supports all arguments both in favor and against. Therefore presently no conclusive evidence or guidelines supports the use or avoidance of such ileostomies. Proponents of routine use argue that the ileostomy does prevent leakage, decrease the detrimental effects of a leak [5] with less major leaks and less reoperation rates [6].

In cases of intestinal perforation or obstruction with features of peritonitis a de-functioning proximal protective loop ileostomy is considered advisable due to presence of one or more of the following intraoperative findings: insecure repair or anastomosis, multiple perforations, matted bowel loops, and grossly unhealthy bowel due to severe edema and inflammation $[7,8]$.

On the other hand, the routine use of ileostomy adds to the morbidity and mortality besides longer hospital stay and costs. Furthermore because ileostomy closure is not a high priority in this era of stringent financial budgeting, it is often postponed or delayed [9]. During this period, stoma-related complications have been reported to range from $9-74 \%$ [10-12].

Even minor complications with the ileostomy significantly hamper the quality of life of these patients. Santulli ileostomy as an alternative to loop ileostomy is an attempt to protect the distal anastomosis and at the same time decrease the ileostomy stoma related complications, and totally avoid the morbidity and mortality associated with stoma takedown. 
Several investigators have reported successful outcomes following laparotomy with Santulli enterostomy in neonates with unresolved uncomplicated meconium ileus unrelieved by contrast enema [13]. Rygl et al. [15] found Santulli ileostomy to be an effective and safe primary repair technique in five extremely low-birth-weight children with localized intestinal damage/perforation.

In our study we noted that complications with Santulli ileostomy in 33\% of patients; was significantly less than the complication rate after the loop ileostomy of 53\%. The peri-stomal complications like skin breakdown, dermatitis, and erythema with loop ileostomy were $16 \%$, in accordance to that reported in the literature ranging from 3-36\% [17]. These problems can be transient but recurrent till ileostomy is closed and usually hamper the proper application of ileostomy appliance making management of ileostomy effluent difficult [18]. In our study local skin problems in Santulli ileostomy were noted in only three patients, however this problem is transient and easily treatable.

Dehydration requiring frequent hospital admissions is a well-known problem after ileostomy due to high ileostomy output. Reported incidence of dehydration ranges from 2.2-20\% [19]. These patients have to be on a stringent diet and anti-diarrheal medication often [20]. Some recommend such measures only if urinary sodium concentration is low $(0-10 \mathrm{meq} / \mathrm{L})$, and delay discharge till effluent is less than $1 \mathrm{~L} / \mathrm{day}$. Four of our patients $22.22 \%$, on loop ileostomy presented with dehydration and electrolyte disturbances requiring readmission.

The other major complications associated with conventional loop ileostomy include prolapse and retraction of bowel loops. Of these retraction is more worrisome as it results in skin excoriation and incomplete de-functioning of the distal anastomosis. This problem is reported to occur in up to $15.9 \%$ of patients [21]. In our study only one patient developed retraction of loop ileostomy which required reoperation.

In patients with Santulli ileostomy output started decreasing from 3rd week as these patients started passing stools per rectum also by 3rd wk. after surgery. Santulli ileostomy closure was also easy and not associated with any major morbidity.

Early bowel obstruction before loop ileostomy reversal has been reported to be due to adhesions, retraction of loop ileostomy, and herniation of proximal bowel lateral to the ileostomy. Stoma-related obstruction occurred in $6.4 \%$ with loop ileostomy in the study reported by Metcalf et al. None of the patients with Santulli ileostomy developed obstruction. Two patients developed obstruction following closure of loop ileostomy of which one required reoperation. There have been reports that the risk of obstruction is less if the ileostomy site is resected and anastomosis performed by stapler [22]. However others have not found any significant difference between the various techniques of closure [20].

Leakage from distal anastomotic site with pelvic sepsis despite proximal loop ileostomy is well known. García-Botello et al. [20] reported $10.24 \%$ anastomotic leak in series of 127 patients despite proximal loop ileostomy. Four patients $(3.15 \%)$ had to be re-operated due to generalized peritonitis, worsening clinical signs, or evidence of sepsis despite conservative management. Feinberg et al. reported a $13.6 \%$ leak rate in their series of 117 patients [18]. Two of our patients with loop ileostomy developed anastomotic leak which was initially managed conservatively; one patient required reoperation due to worsening clinical signs.

Other complications have been frequently reported with delay in the ileostomy closure or the takedown itself. Gallstones occur with gallstone pancreatitis especially if the ileostomy closure is delayed [18]. Anastomotic leaks from ileostomy reversal site in up to $8.3 \%$ are mentioned in the literature $[17,19]$. The incidence of wound infection has been reported from 1.3\%-18.3\% while incisional hernia occurs in up to $11.9 \%$ of patients after ileostomy closure [17]. All these morbidities are avoided with the use of Santulli ileostomy.

We feel a complete de-functioning ileostomy is not necessary for anastomosis healing and an adequate decrease in flow across the anastomosis using proximal ileostomy is enough. Also for successful Santulli ileostomy, care must be taken to place it in healthy segment of bowel. Very proximal placement leads to high volume ileostomy output. Further large scale well-designed, randomized control trials are needed to compare Santulli ileostomy as an alternative to conventional loop ileostomy as a diversion procedure in neonates requiring diversion.

\section{Conclusion}

Santulli ileostomy has been found to be a better alternate diversion procedure with few complications and was easy to construct and manage as compared to conventional ileostomy. It effectively diverts the bowel contents and avoids the need for an early second surgery and its related complications. Further larger randomized studies need to be undertaken before Santulli ileostomy could be recommended as an alternative to loop ileostomy as a diversion procedure. 


\section{References}

[1]. J. C. Duchesne, Y. Z. Wang, S. L. Weintraub, M. Boyle, and J. P. Hunt, "Stoma complications: a multivariate analysis," American Surgeon, vol. 68, no. 11, pp. 961-966, 2002. View at Google Scholar · View at Scopus

[2]. K. P. Riesener, W. Lehnen, M. Höfer, R. Kasperk, J. C. Braun, and V. Schumpelick, "Morbidity of ileostomy and colostomy closure: impact of surgical technique and perioperative treatment," World Journal of Surgery, vol. 21, no. 1, pp. 103-108, 1997. View at Publisher - View at Google Scholar · View at Scopus

[3]. L. J. Mann, P. J. Stewart, R. J. Goodwin, P. H. Chapuis, and E. L. Bokey, "Complications following closure of loop ileostomy," Australian and New Zealand Journal of Surgery, vol. 61, no. 7, pp. 493-496, 1991. View at Google Scholar · View at Scopus

[4]. R. B. Turnbull Jr. and F. L. Weakley, "Ileostomy technics and indications for surgery," Review of Surgery, vol. 23, no. 5, pp. 310314, 1966. View at Google Scholar . View at Scopus

[5]. E. Carlsen and A. B. Bergan, "Loop ileostomy: technical aspects and complications," European Journal of Surgery, vol. 165, no. 2, pp. 140-144, 1999. View at Publisher · View at Google Scholar · View at Scopus

[6]. D. F. Altomare, O. C. Pannarale, L. Lupo, N. Palasciano, V. Memeo, and M. Rubino, "Protective colostomy closure: the hazards of a "minor" operation," International Journal of Colorectal Disease, vol. 5, no. 2, pp. 73-78, 1990. View at Publisher · View at Google Scholar . View at Scopus

[7]. K. P. Singh, K. Singh, and J. S. Kohli, "Choice of surgical procedure in typhoid perforation: experience in 42 cases," Journal of the Indian Medical Association, vol. 89, no. 9, pp. 255-256, 1991.View at Google Scholar • View at Scopus

[8]. H. N. Ahmed, M. P. Niaz, M. A. Amin, M. H. Khan, and A. B. Parhar, "Typhoid perforation still a common problem: situation in Pakistan in comparison to other countries of Low Human Development," Journal of the Pakistan Medical Association, vol. 56, no. 5, pp. 230-232, 2006. View at Google Scholar · View at Scopus

[9]. M. Kairaluoma, H. Rissanen, V. Kultti, J. P. Mecklin, and I. Kellokumpu, “Outcome of temporary stomas: a prospective study of temporary intestinal stomas constructed between 1989 and 1996,'Digestive Surgery, vol. 19, no. 1, pp. 45-51, 2002. View at Publisher · View at Google Scholar · View at Scopus

[10]. J. H. Saghir, F. D. McKenzie, D. M. Leckie et al., "Factors that predict complications after construction of a stoma: a retrospective study," European Journal of Surgery, vol. 167, no. 7, pp. 531-534, 2001. View at Publisher · View at Google Scholar · View at Scopus

[11]. J. J. Park, A. Del Pino, C. P. Orsay et al., "Stoma complications: the Cook County Hospital experience," Diseases of the Colon and Rectum, vol. 42, no. 12, pp. 1575-1580, 1999. View at Google Scholar · View at Scopus

[12]. G. C. O'Toole, J. M. P. Hyland, D. C. Grant, and M. K. Barry, "Defunctioning loop ileostomy: a prospective audit," Journal of the American College of Surgeons, vol. 188, no. 1, pp. 6-9, 1999. View at Publisher · View at Google Scholar · View at Scopus

[13]. G. Z. Mak, F. J. Harberg, P. Hiatt, A. Deaton, R. Calhoon, and M. L. Brandt, "T-tube ileostomy for meconium ileus: four decades of experience," Journal of Pediatric Surgery, vol. 35, no. 2, pp. 349-352, 2000. View at Google Scholar · View at Scopus

[14]. E. A. Lizarralde, "Typhoid perforation of the ileum in children," Journal of Pediatric Surgery, vol. 16, no. 6, pp. 1012-1016, 1981. View at Google Scholar . View at Scopus

[15]. M. Rygl, K. Pycha, Z. Stranak et al., "T-tube ileostomy for intestinal perforation in extremely low birth weight neonates," Pediatric Surgery International, vol. 23, no. 7, pp. 685-688, 2007. View at Publisher · View at Google Scholar · View at Scopus

[16]. K. Hojo, "Total colectomy, rectal mucosectomy and ileoanal anastomosis for familial polyposis coli - use of tube ileostomy," Japanese Journal of Clinical Oncology, vol. 15, no. 4, pp. 661-669, 1985.View at Google Scholar · View at Scopus

[17]. H. D. W. M. Van De Pavoordt, V. W. Fazio, D. G. Jagelman, I. C. Lavery, and F. L. Weakley, "The oucome of loop ileostomy closure in 293 cases," International Journal of Colorectal Disease, vol. 2, no. 4, pp. 214-217, 1987. View at Google Scholar · View at Scopus

[18]. S. M. Feinberg, R. S. McLeod, and Z. Cohen, "Complications of loop ileostomy,” American Journal of Surgery, vol. 153, no. 1, pp. 102-107, 1987. View at Google Scholar · View at Scopus

[19]. S. D. Wexner, D. A. Taranow, O. B. Johansen et al., "Loop ileostomy is a safe option for fecal diversion," Diseases of the Colon and Rectum, vol. 36, no. 4, pp. 349-354, 1993. View at Google Scholar · View at Scopus

[20]. S. A. García-Botello, J. García-Armengol, E. García-Granero et al., "A prospective audit of the complications of loop ileostomy construction and takedown," Digestive Surgery, vol. 21, no. 5-6, pp. 440-446, 2004. View at Publisher · View at Google Scholar · View at Scopus

[21]. A. M. Metcalf, R. R. Dozois, and R. W. Beart Jr., "Temporary ileostomy for ileal pouch-anal anastomosis: function and complications," Diseases of the Colon and Rectum, vol. 29, no. 5, pp. 300-303, 1986. View at Google Scholar · View at Scopus

[22]. H. Hasegawa, S. Radley, D. G. Morton, and M. R. B. Keighley, "Stapled versus sutured closure of loop ileostomy. A randomized controlled trial," Annals of Surgery, vol. 231, no. 2, pp. 202-204, 2000. View at Publisher · View at Google Scholar · View at Scopus

[23]. F. Rondelli, R. Balzarotti, W. Bugiantella, L. Mariani, R. Pugliese, and E. Mariani, "Temporary percutaneous ileostomy versus conventional loop ileostomy in mechanical extraperitoneal colorectal anastomosis: a retrospective study," European Journal of Surgical Oncology, vol. 38, no. 11, pp. 1065-1070, 2012. View at Google Scholar 